\title{
Enhancing Student Employability: A Conceptual Frame Work and Scale Development for Engineering Students
}

\author{
Murali . S And Dr. Y Rajaram \\ Research and Development Centre, Bharathiar University; Coimbatore- 641046 \\ Ramaiah Institute of Management Studies, Bangalore- 560054
}

\section{Introduction}

Enhancing student employability has always engaged students in need of making them acquire quality skills in order to be ready of fully engaging themselves as a part of the labor force. However, for engineering students, there is a much wider undertaking on how they can conceptualize their knowledge and skills as well as aptitude in order to get a job. As the modern world is taking on a more dynamic constructional structure of inventing digital technologies, it is inevitable to realize that the supply of engineering job positions and the demand for engineering students will continue to gradually rise in the future but the main problem faced by the engineering students is the actual demand and supply factor of the graduates which has been leaving a very big gap. This paper therefore is going to address some ideas that can enhance the employability rate of engineering students in order to reduce and eventually eradicate this skills gap (University of Colorado, 2013). Keywords: Employability, Scale Development

\section{A Conceptual Framework of Enhancing Student Employability}

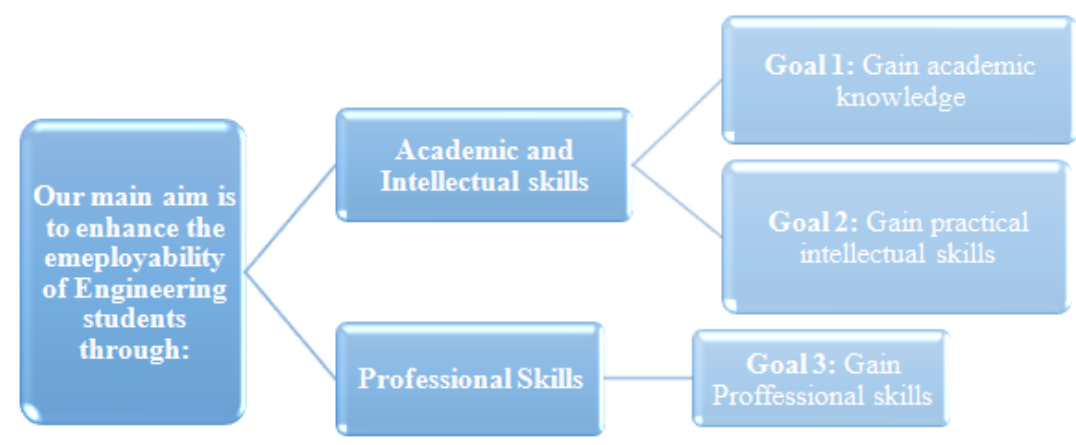

Goals and Objectives
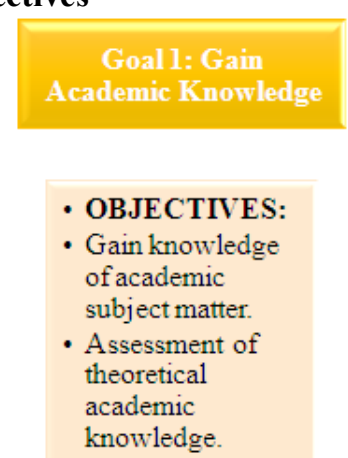

\section{Goal 2: Gain Practical Intellectual Skills}

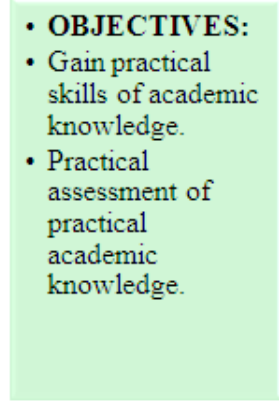

Goal 3: Gain

Proffessional Skills

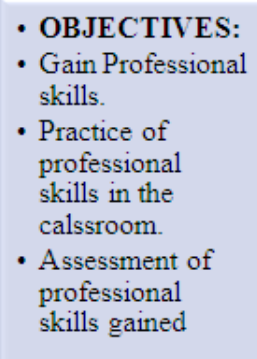

The engineering students will need to first acquire the academic and intellectual skills that will program their mental skills and practical skills in the manner required for each of their specialized field of study.

Goal 1: Gain Academic Knowledge. Academic knowledge of the engineering students will be vital as they understand each concept and theory articulated with each of the subject matter contained in their fields of study. The following objectives are entailed in achieving this goal:

1. Gain knowledge of academic subject matter. 
The engineering students need to understand how each theory explains a modeled concept. This will enhance their intellectual understanding especially in the practical application of these understanding.

- The outcome of this is that the students will be able to realize the importance of always enhancing their knowledge both in the classroom and even later on in the work place.

2. Assessment of theoretical academic knowledge.

- The target outcome of this objective is that to ensure that each student will have a sharp memory of what they have learned in order to not struggle with understanding the practical application of engineering skills.

Goal 2: Gain Practical Intellectual Skills. The engineering students will have to continually participate in practical experiments that apply the theoretical concepts taught in the curriculum. This will ease their transitive knowledge into practical knowledge that can be easily utilized. This will also enhance their intellectual skills as they will be more familiar with the equipments they shall be operating once they merge into the labor market. The specific objectives articulated to this goal are:

1. Gain practical skills of academic knowledge.

- This is very necessary as majority of the work conducted in engineering fields is very practical. It requires the fast ability to take the theoretical knowledge and know how to practically use it with the engineering equipments they will be handling.

The outcome of this objective is that the students will already have all the basic skills required to responsibly manage their jobs and be in a better position to gain higher level of skills.

2. Practical assessment of practical academic knowledge.

- Their practical skills will be assessed and graded in order to have them recognize their strengths and weaknesses and know which areas to work on more in order to be effective.

The engineering students have been found to posses the academic and intellectual skills but have been discredited in the job market due to lack of professional skills which is a very important skill to acquire during their university years.

Goal 3: Gain Professional skills. This is a very important factor in the labor market as each graduate student needs to have the basic professional skills required to merge into the job market such as professional communication skills, decision making skills and pressure management among others. The objectives that will exhibit the accomplishment of this goal are the following:

1. Gain Professional skills.

- $\quad$ The student will need to have their soft skills to be trained in order for those to complement their hard skills.

- The student will be more prepared on how to handle their first interviews and how to communicate to their superiors upon approval of a job position.

- $\quad$ The student will be able to contribute these skills to enhance the success of the company

2. Practice of professional skills in the classroom.

- The student will need to continually practice the gained skills on a day to day basis in order to master the art of behaving in a professional manner.

- $\quad$ This will be done by expecting them to communicate with each other in a professional manner as well use practical cases in the classroom for the students to perform.

- $\quad$ The outcome of this objective is that every student will be able to gain a great level of confidence in utilizing these professional skills daily.

- The outcome of this objective is that the students will master these skills and be able to articulate these skills without any complication.

3. Assessment of professional skills gained.

The students will undergo practical assessments in order to realize their weaknesses and strengths in the practical application of the professional skills. One of the tests would be how they handle interview questions verbally or a customer complaint, for example. This assessment will be graded and they will be advised on which areas they need to continually work on.

- The outcome of this assessment is that students will have a more solid ground of realizing the progress of their professional skills and continually enhance them.

\section{Elements of framework}

Quality education. Every student should be entitled to receiving quality education that readily prepares them for the job requirements and challenges. In New Delhi, India, less than twenty percent of the software graduate engineers were able to secure employability (Economic Times, 2014). This occurred majorly due to the low standards of education levels whereas the market requires highly skilled employees that they can easily train (Aggarwal, 2014). Even with a high supply of applicants, majority of the graduates were turned down as they were reported to not have the basic skill required in order to enter the work environment (Pathshala, 2012). 
Professionalism. Professionalism depicts the official persona in which each graduate student should be able to practically show in how they relate to their interviewers, co- workers, customers and bosses. Do they lose their temper under pressure or can they control it well enough to undertake their duties in stride?

Employability. Graduates need to be fully aware of the professional skills requires by the job they are applying for and with engineering, they need to have updated skills required in the industry. The employability rate of engineers is valued at a much lower rate than the annual graduates who are ready to enter the labor market. The first thing that is realized in this concept is that it is not just about talent in the profession but much more about the basic skills and requirement for employment approval.

\section{Discussion of the Framework}

Theoretical Framework

Employability has for long been given several definitions that enhance the understanding of what it is such as:

1. Harvey defined employability as a process of learning whereby an individual will acquire a greater level of experience and will continue to develop themselves as one is not believed to stop learning after schooling but will undergo a continuous process of education throughout their employment years (Harvey, 2001).

2. Bernston brought up a different kind of argument as he states; employability is the perception of an individual towards their own possibility of getting a new, better or equal employment opportunity (Berntson, 2008).

The ideal rational definition of employability has something to do with the recognition of the human race as they remain productive in their respective professions whether it is a highly-paying job or not. It is concerned with the ability to not only utilize the currently acquired skills and knowledge but also the ability to acquire a much higher level of skills and knowledge in an expounding environment where challenges are presented to enhance the potential of the employees. Employability endorses sustainability, developments and progress in adversity and professional growth.

\section{Demand and Supply factors of Employability in Engineering Professions}

As already mentioned above the demand and supply of engineers employability ratio provides a very big difference due to the following factors:

1. The retirement of highly qualified professional engineers is occurring at a rapid rate due to their age. Thus creating more room for employability of engineering graduates.

2. There is a high demand for highly qualified graduates for employability but the supply is low due to the fact that companies only hire graduates from prestigious universities.

3. Education standards level is very different in other colleges and institutions as they will provide an education level that is primary to the graduates in prestigious universities. Hence the graduating engineers are found to not be prepared for employability due to low level skills and knowledge.

4. Due to the radical development of nations and the rapid development to technologies engineering job position demands will continually grow higher than the qualified supply available.

5. Graduates are not fully aware of the high quality skills they need to have acquired before merging into the job market is also a hindering factor that promotes low supply of engineers in comparison to the high demand for them (Ladimeji, 2014).

Some of the engineering professions that are high in demand include: industrial engineers, electrical engineers, chemical engineers, petroleum engineers, mining and geological engineers, marine engineers, industrial safety and health engineers (Ladimeji, 2014). Each of the engineering specialized professions offer graduate students with a grand opportunity to start off with a competitive salary that will continually enhance as they improve their job positions in the industry.

Both demand and supply factors attribute a great effect on the employability in almost any field of expertise. Engineering graduates can look at some of the demand factors that determine employability rate such as (Ronald, McQuaid \& Colin, 2004):

1. Labor market. This includes knowing:

- $\quad$ The level of competition in the labor markets,

- $\quad$ The local and regional demand of engineering employability,

- $\quad$ Customer preferences of the services provided in their engineering professions,

- The national economy and stability of the engineering companies they are applying to,

- $\quad$ The recruitment requirements (both formal and informal) in the labor market,

- The conditions of the job position i.e. work hours, progression opportunities etc.

2. The supporting factors that will enhance the growth and development opportunity in the job position such as

- $\quad$ The employment policy both for the nation and for the hiring company 
- $\quad$ Benefits such as tax benefits accrued in the work placement

- Job traineeship programs to help enhance your skills

- $\quad$ Any other policies entailed in the job position acquisition such as accessibility to affordable and public services e.g. transportation and childcare services

As already mentioned above it is very clear that the supply side of engineering graduates is cut at almost eighty percent due to the inability to fulfill the employability requirements of the labor market. The best ways to reduce this effect and enhance the supply side is by having the engineering companies create substantive methods to eradicate this skill gap. One way is set as a great example is by providing traineeship programs to the disqualified engineering graduates as currently done by Zensar Technologies in India. This will enhance the ability to acquire higher level skills with additional practical skills enhancement for the fresh graduate students. If ten more companies participated in the same type of program they would be able to educate ten times the population of graduate engineers and thus enhance the ration of employment while decreasing the low level of supply side factor.

Another way to influence the increased levels of the supply side factor in employability would be in contributing valuable information to colleges and institutions on the expected developments of each engineering profession. This will enable the tutors to level the course model to entail the teaching of this knowledge and skills to their students and enhance their employability qualifying levels. These engineering companies should have some level of construed influence on the syllabus changes in order to have the education system fully upgraded to their professional requirements of each graduating student.

\section{How it Works}

The three main goals of this framework are to gain: academic knowledge, intellectual practical skills and professional skills. In order to do this, the education system of engineering needs to be continually updated with the new findings in the industry. Engineering is constantly developing and the new knowledge needs to be passed on to the students through their curriculum no matter which university they are studying in.

The students need to gain practical intellectual skills which are better gained in a viable company. The education system needs to attach employment of student to various companies while they study. This should be done as soon as the students begin their first semester. This will enhance their fieldwork experience as well enhance their understanding of the study material. An assessment conducted on the work they have been conducting during the semester should be assessed in order to analyze their progress and this should be done by both their tutors and their supervisors at the workplace.

The job market requires individuals who can work with other co-workers and customers even when the pressure is very high. One way is by conducting a soft skills training for the student in the class room and the practical approach will enhance better results than just giving them a lecture about it. Practical assessment as to how they are continually applying these professional skills will be found in the manner in which they operate in both the classroom and attachment employment areas throughout their study years.

For this process to produce a successful achievement among all the students, the training process is always the first step, then the practical guidance is the second step then the assessment is done to verify the student's progress in each of these areas.

\section{Conclusion}

Enhancing employability for engineering students all begins in the classroom. Every student has the potential to achieve high academic and practical engineering skills if they have the right guidance and tools to get them there. This should begin with attributing a very high esteem towards integrating a futuristic view on their life and goals. Secondly the tutor should give a clear picture of the current developments in the labor market and engineering companies. This will act as a guiding tool towards each student developing a map on how they will achieve high quality skills and experience, required to enhance their employability opportunity. If some of the student would much rather venture into creating a private business they should be supplied with the relevant information on the competition in the same industry and understand their value of increasing job position demand in the labor market. They should understand why the demand and supply factors create limitations to hiring graduate students and be encouraged to formulate and implement strategic approaches to tackle these limitations.

Getting into the labor market can make one feel very nervous especially if they are not confident in their skills and barely understand the basic experience entailed in this process. Preparation and practice is a good way to adjust to the demands of the labor market. 


\section{References}

[1]. Aggarwal, H. (2014). Software engineering jobs. Employability rate. Retrieved from: http://articles.economictimes.indiatimes.com/2014-07-14/news/51484811_1_national-employability-report-amcat-software-jobs

[2]. Berntson, E. (2008). Employability Perceptions: Nature, Determinants and Implication for Health and Well-being. Sweden, UK: Department of Psychology, Stockholm University.

[3]. Economic Times. (2014). Less than 20 percent engineers are employable for software jobs. Economic Times: India Times. Retrieved from: http://articles.economictimes.indiatimes.com/2014-07-14/news/51484811_1_national-employability-report-amcatsoftware-jobs

[4]. Harvey, L. (2001). Defining and measuring employability. Quality in Higher Education, 7(2).

[5]. Ladimeji, K. (2014). 10 most in demand engineering jobs for 2014 (US). The career café. Retrieved from: http://thecareercafe.co.uk/blog/?p=12223

[6]. Pathshala. (2012). Bridging the employability gap in Indian IT industry by effective employability training. An employability report on IT \&ITES industry. Retrieved from: http://www.slideshare.net/itpathshala/employability-gap-in-indian-it-industry

[7]. Ronald, W., McQuaid, and Colin, L. (2004). The concept of Employability. Urban Studies, Vol. 42, No. 2, pg 197-219.

[8]. University of Colorado. (2013). Engineering jobs experience high demand in 2013. Civil, Environmental and Architectural Engineering. Retrieved from: http://civil.colorado.edu/2013/05/22/engineering-jobs-experience-high-demand-in-2013/ 